\title{
Use of implantable cardioverter defibrillators after out-of-hospital cardiac arrest: a prospective follow-up study
}

\author{
Ratika Parkash, Anthony Tang, George Wells, Josée Blackburn, Ian Stiell, Christopher Simpson, \\ Paul Dorian, Raymond Yee, Doug Cameron, Stuart Connolly, David Birnie, Graham Nichol
}

ß See related article page 1037

Abstract

Background: Survivors of out-of-hospital cardiac arrest are at high risk of recurrent arrests, many of which could be prevented with implantable cardioverter defibrillators (ICDs). We sought to determine the ICD insertion rate among survivors of out-ofhospital cardiac arrest and to determine factors associated with ICD implantation.

Methods: The Ontario Prehospital Advanced Life Support (OPALS) study is a prospective, multiphase, before-after study assessing the effectiveness of prehospital interventions for people experiencing cardiac arrest, trauma or respiratory arrest in 19 Ontario communities. We linked OPALS data describing survivors of cardiac arrest with data from all defibrillator implantation centres in Ontario.

Results: From January 1997 to April 2002, 454 patients in the OPALS study survived to hospital discharge after experiencing an out-of-hospital cardiac arrest. The mean age was 65 (standard deviation 14) years, 122 (26.9\%) were women, 398 $(87.7 \%)$ had a witnessed arrest, $372(81.9 \%)$ had an initial rhythm of ventricular tachycardia or ventricular fibrillation (VT/F), and 76 (16.7\%) had asystole or another arrhythmia. The median cerebral performance category at discharge (range $1-5,1=$ normal) was 1 . Only $58(12.8 \%)$ of the 454 patients received an ICD. Patients with an initial rhythm of VTNF were more likely than those with an initial rhythm of asystole or another rhythm to undergo device insertion (adjusted odds ratio [OR] 9.63, 95\% confidence interval [Cl] 1.31-71.50). Similarly, patients with a normal cerebral performance score were more likely than those with abnormal scores to undergo ICD insertion (adjusted OR 12.52, 95\% Cl 1.74-92.12).

Interpretation: A minority of patients who survived cardiac arrest underwent ICD insertion. It is unclear whether this low usage rate reflects referral bias, selection bias by electrophysiologists, supply constraint or patient preference.

CMAJ 2004;171(9):1053-6

$\mathrm{P}$ eople who survive out-of-hospital cardiac arrest have an increased risk of recurrent arrest of $18 \%-20 \%$ in the first year., ${ }^{1,2}$ Three large randomized studies evaluated the use of implantable cardioverter defibrillators (ICDs) versus antiarrhythmic drugs in survivors of out-ofhospital cardiac arrest. ${ }^{3-5}$ The largest of the 3 studies in- volved 1016 patients and found a 39\% relative risk reduction in mortality in the ICD group. ${ }^{3}$ The 2 smaller studies both reported nonsignificant reductions in mortality in the ICD group., ${ }^{4,5}$ Two recent meta-analyses showed that the use of ICDs was associated with significant and important increases in survival among cardiac arrest survivors: allcause mortality was reduced by $23 \%-28 \%$ with their use for secondary prevention, and the rate of sudden cardiac death was reduced by $50 \%$ in both meta-analyses. ${ }^{6,7}$

Guidelines from several national and international societies recommend insertion of ICDs in all survivors of cardiac arrest without a reversible cause., ${ }^{8,9}$ Despite advances in ICD insertion and technology, studies to date suggest that the utilization rate is low, at least in some settings. ${ }^{10,11}$ Several factors, including patient preference, physician referral, availability and cost, may contribute to the underutilization of ICDs.

The Ontario Prehospital Advanced Life Support Study (OPALS $)^{12,13}$ is a multiphase before-after study designed to systematically evaluate the effectiveness of various prehospital interventions for people experiencing cardiac arrest, trauma or respiratory arrest. As an extension of the OPALS study, we sought to determine the rate of ICD insertion among survivors of cardiac arrest, as well as the factors associated with ICD implantation.

\section{Methods}

The OPALS study included all patients who experienced an out-of-hospital cardiac arrest, trauma or respiratory arrest from 1994 to 2002 and on whom resuscitation was attempted by emergency responders. The methodology of the study for cardiac arrest patients has been described previously. ${ }^{12,13}$ In brief, the study took place in 19 urban and suburban Ontario communities with populations of 12000 to 750000 . All patients were included who had an arrest of presumed cardiac cause from January 1997 to April 2002 and for whom resuscitation by an emergency medical services responder was attempted, following the Utstein guidelines, ${ }^{14}$ and who survived to hospital discharge. Cardiac arrest was defined as the absence of a detectable pulse, unresponsiveness and apnea. The 11 base hospital sites - Halton-Mississauga, Cambridge, Kingston, Niagara, London, Ottawa, Peterborough, Sarnia, Sudbury, Thunder Bay and Windsor - collected the fol- 
lowing information on each patient: clinical and demographic characteristics, ambulance call reports, rhythm records, dispatch reports and in-hospital records. A discharge assessment of disease-specific quality of life was represented by the cerebral performance category $(1$ good performance, 2 = moderate disability, 3 = severe disability, $4=$ coma or vegetative state, and $5=$ brain death). ${ }^{15}$

For our substudy, we linked OPALS data describing survivors of cardiac arrest with data from all 7 ICD implantation centres in Ontario to determine which of the OPALS cardiac arrest patients ultimately received an ICD. The implantation centres were the London Health Sciences Centre, the Toronto General Hospital, St. Michael's Hospital, Sunnybrook and Women's College Health Sciences Centre, the Hamilton Health Sciences Centre, the Kingston General Hospital and the Ottawa Heart Institute. The study design was approved by the Ottawa Hospital Research Ethics Board and by ethics review boards at each participating institution with a waiver of informed consent.

We examined continuous variables by using Student's $t$ test and categorical variables by using the $\chi^{2}$ test. The $\chi^{2}$ test for trend was used where appropriate. Multivariate analysis was conducted with logistic regression using a backward elimination model. Factors considered in our analysis included age, sex, initial rhythm, whether or not the arrest was witnessed, cerebral performance category at discharge, year of implant, community size and number of practising cardiologists in each community. These factors were chosen a priori to be included in the multivariate model. No information on comorbidities or other patient factors were available for analysis. All reported confidence intervals were using a $95 \%$ cutoff. All significance tests were 2 -sided, and a $p$ value of less than 0.05 was chosen as the cutoff for achieving statistical significance.

\section{Results}

During the study period 8710 people experienced cardiac arrest on whom resuscitation was attempted. Of these, $2396(27.5 \%)$ were pronounced in the field, $1210(13.9 \%)$ survived to be admitted to hospital, and 454 (5.2\%) survived to hospital discharge (Table 1$)$. The mean age of those who survived to hospital discharge was 65 (standard deviation [SD] 14) years; $122(26.9 \%)$ were women and $398(87.7 \%)$ had a witnessed arrest. The majority presented with ventricular tachycardia or ventricular fibrillation (VT or VF).

The ICD implantation rate was $12.8 \%$ (58/454). The

Table 1: Characteristics of patients who experienced out-of-hospital cardiac arrest and survived to hospital discharge

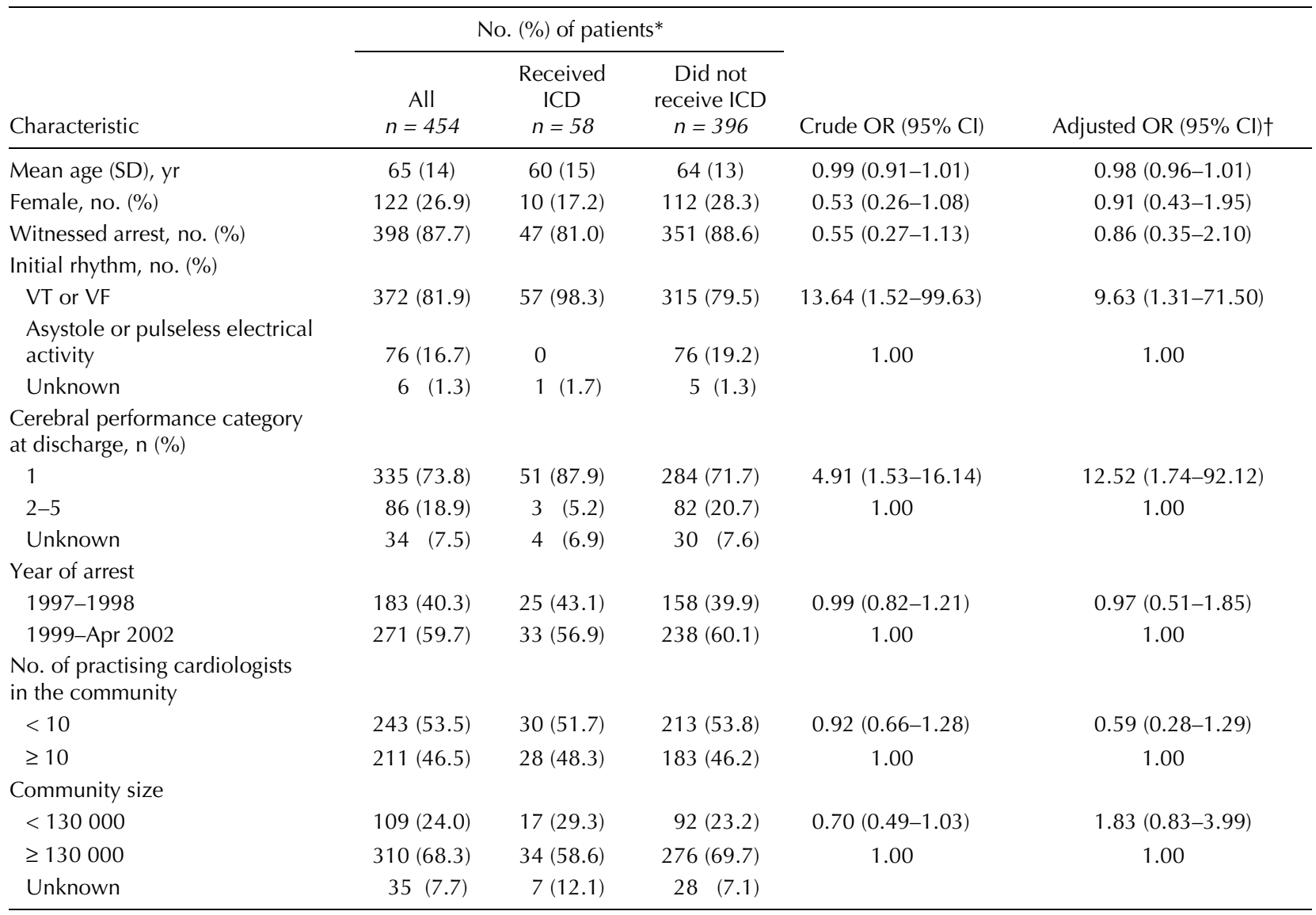

Note: $\mathrm{ICD}=$ implantable cardioverter defibrillator, $\mathrm{OR}=$ odds ratio, $\mathrm{Cl}=$ confidence interval, $\mathrm{SD}=$ standard deviation, $\mathrm{VT}=$ ventricular tachycardia, $\mathrm{VF}=$ ventricular fibrillation *Unless stated otherwise.

†Adjusted for age, sex, initial rhythm, whether arrest was witnessed, cerebral performance category at discharge, year of arrest, community size and number of practising cardiologists in each community. 
median time from cardiac arrest to ICD implantation was 3 weeks (range 1-203 weeks). There was no significant difference in age, sex or whether the arrest had been witnessed between the patients who received an implant and those who did not (Table 1).

Factors significantly associated with ICD insertion were initial rhythm at time of arrest and neurological status (as determined by the cerebral performance score) at discharge. All but 1 of the 58 patients who received an implant had an initial rhythm of VT or VF at the time of their cardiac arrest, as compared with $79.5 \%(315 / 396)$ of the patients who did not receive an implant $(p<0.001)$. Overall, 335 (73.8\%) of the patients had a cerebral performance score of 1 (normal). The proportion of patients with a normal score was higher in the ICD group than in the group who did not receive an ICD $(87.9 \%$ v. $71.7 \%$, $p=0.003)$. Three $(5.2 \%)$ of the patients who received an implant had a mildly abnormal neurological status; for 4 patients who received an implant the neurologic status was unknown (Table 1).

The ICD insertion rate among survivors during 19971998 was $11.5 \%(21 / 183)$, the highest rate occurring in 1997 (16.0\% [15/94]) (Fig. 1). A trend toward an increased insertion rate was observed over time $(p=0.14)$. There was no association between community size $(p=0.06)$ or number of practising cardiologists in each community $(p=0.17)$ and the likelihood of ICD insertion.

In the multivariate analysis, we found that 2 factors were independently associated with ICD insertion: a rhythm of VT or VF at the time of cardiac arrest (adjusted odds ratio [OR] 9.63, 95\% confidence interval [CI] 1.31-71.50) and a normal neurological status at hospital discharge (adjusted OR 12.52, 95\% CI 1.74-92.12).

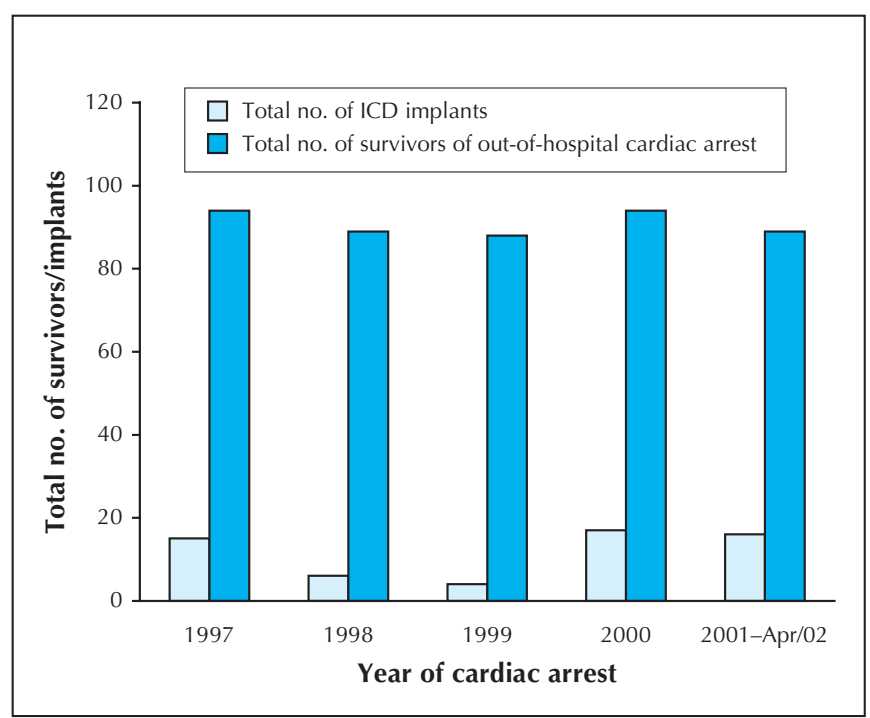

Fig. 1: Number of patients in 19 urban and nonurban communities in Ontario who experienced out-of-hospital cardiac arrest and survived to hospital discharge and number who received an implantable cardioverter defibrillator.

\section{Interpretation}

This study we found that, in selected communities in Ontario, only a minority of such patients received an implant, despite the strong evidence of its benefit in this highrisk population. Patients with an initial rhythm of VT or $\mathrm{VF}$ and those who had a normal neurological status after resuscitation had an increased likelihood of undergoing ICD insertion.

Previous studies showed low insertion rates among survivors of cardiac arrest, ${ }^{10,11}$ but they were higher than the rate observed in this study. Ruskin and colleagues ${ }^{10}$ examined data from managed care and Medicare databases. After adjustment for potential factors that might preclude ICD insertion, they found an insertion rate of approximately $34 \%$. Kliegel and associates ${ }^{11}$ reported an insertion rate of $16 \%$ in a single-centre study in Austria.

Unlike Kliegel and associates, we examined a large prospective cohort in 19 urban and suburban communities of Canada. The expected rate of ICD implantation among survivors of out-of-hospital cardiac arrest is $40 \%-50 \% .{ }^{16}$ We found the actual rate in our study to be much lower $(12.8 \%)$, which means that a significant proportion of this patient population did not receive a proven and life-saving therapy.

Several factors may explain our findings. The lack of referral of patients to ICD implant centres may be a significant factor. Many of the base hospitals in the OPALS study had no onsite electrophysiologists. A direct relation between utilization of services, particularly invasive procedures, and in-hospital availability of specialists has been shown in other settings, such as the use of cardiac catheterization after myocardial infarction. ${ }^{17}$ Patients may not be referred to an ICD centre for assessment because of lack of accessibility to tertiary care, lack of availability of ICDs or a perceived supply constraint owing to cost. For example the number of defibrillators available for implantation is determined by an annual quota set by the government.

Patient preference to forego ICD insertion may also play a role. However, poor quality of life of survivors is unlikely to explain the low implant rate, since it has been shown that most survivors of cardiac arrest have acceptable functional status ${ }^{18}$ and health-related quality of life. ${ }^{19-21}$

Finally, the low insertion rate may be attributed in part to a lag in physicians learning about the effectiveness of ICD implantation, since reports of clinical trials supporting this therapy were first published in $1997 .^{3-5}$ This explanation is supported by our observation of a trend toward an increase in ICD insertion in more recent years.

The primary limitation of our study is that we were unable to assess left ventricular function, the presence of comorbidities, or transient, reversible causes of cardiac arrest that might preclude ICD insertion. Less than $50 \%$ of patients who experience cardiac arrest may have a transient, reversible cause. ${ }^{22}$ However, it is unclear whether such pa- 
tients are at low risk after their index event. Recent evidence suggests that survivors of cardiac arrest with a reversible cause, such as ischemia, are at increased risk of future arrests. ${ }^{1,23}$ In an analysis of such patients in the AVID registry, the risk of future cardiac arrest among survivors with a transient or reversible cause was as high as the risk among those with primary VT or VF. ${ }^{24}$

The OPALS study did not include large urban centres in Ontario and therefore may have missed a substantial number of patients who survived cardiac arrest. However, this omission would likely not affect the overall ICD insertion rate that we observed, since ICD implants occur exclusively at urban centres.

\section{Conclusion}

People who survive out-of-hospital cardiac arrest are at high risk of recurrent arrest in the first year. We have shown that the majority of these patients are not undergoing ICD insertion despite their having a normal neurological status at discharge from hospital and the procedure's proven benefit.

This article has been peer reviewed.

From the Ottawa Heart Institute (Parkash, Tang, Birnie), the Ottawa Health Research Institute (Wells, Blackburn, Nichol), and the Department of Emergency Medicine, University of Ottawa (Stiell), Ottawa, Ont.; the Kingston General Hospital, Kingston, Ont. (Simpson); St. Michael's Hospital (Dorian) and the Toronto General Hospital (Cameron), Toronto, Ont.; the London Health Sciences Centre (Yee), London, Ont.; and the Hamilton Health Sciences Centre (Connolly), Hamilton, Ont.

Competing interests: None declared for Ratika Parkash, George Wells, Josée Blackburn, Ian Stiell, Raymond Yee, Doug Cameron, Stuart Connolly and Graham Nichol. Anthony Tang has received educational and research grants from Medtronic Inc., Guidant Corp. and St. Jude Inc. Christopher Simpson has received honoraria and speaker fees from Medtronic Inc. and Guidant Corp. Paul Dorian has received educational grants from Medtronic Inc., Guidant Corp. and St. Jude Inc. David Birnie has received speaker fees from Medtronic Inc. and sponsorship to attend a meeting from Guidant Corp.

Contributors: The article was drafted by Ratika Parkash and Graham Nichol. Ratika Parkash, Anthony Tang, George Wells, Ian Stiell and Graham Nichol contributed substantially to the conception and design of the study. All of the authors contributed to the acquistion, analysis and interpretation of the data, revised the manuscript critically for important intellectua/l content and gave their final approval of the version to be published.

Acknowledgement: This research was sponsored in part by an unrestricted grant from Medtronic of Canada Inc. Dr. Stiell is a distinguished investigator, Canadian Institute of Health Research.

\section{References}

1. Anderson JL, Hallstrom AP, Epstein AE, Pinski SL, Rosenberg Y, Nora MO, et al. Design and results of antiarrhythmics vs. implantable defibrillators (AVID) registry. Circulation 1999;99(13):1692-9.

2. Goldstein S, Landis JR, Leighton R, Ritter G, Vasu CM, Wolfe RA, et al. Predictive survival models for resuscitated victims of out-of-hospital cardiac arrest with coronary artery disease. Circulation 1985;71(5):873-80.

3. A comparison of antiarrhythmic drug therapy with implantable defibrillators in patients resuscitated from near fatal ventricular arrhythmias. The Antiarrhythmics versus Implantable Defibrillators (AVID) Investigators: $N$ Engl $7 \mathrm{Med}$ 1997;337:1576-83.

4. Connolly SJ, Gent M, Roberts RS, Dorian P, Roy D, Sheldon RS, et al. Canadian implantable defibrillator study (CIDS): a randomized trial of the implantable cardioverter defibrillator against amiodarone. Circulation 2000;101(11):1297-302.

5. Kuck KH, Cappato R, Siebels J, Ruppel R. Randomized comparison of antiarrhythmic drug therapy with implantable defibrillators in patients resusci- tated from cardiac arrest: the Cardiac Arrest Study Hamburg (CASH). Circulation 2000;102(7):748-54.

6. Ezekowitz JA, Armstrong PW, McAlister FA. Implantable cardioverter defibrillators in primary and secondary prevention: a systematic review of randomized, controlled trials. Ann Intern Med 2003;138:445-52.

7. Connolly SJ, Hallstrom AP, Cappato R, Schron EB, Kuck KH, Zipes DP, et al. Meta-analysis of the implantable cardioverter defibrillator secondary prevention trials. AVID, CASH and CIDS studies. Antiarrhythmics vs Implantable Defibrillator study. Cardiac Arrest Study Hamburg. Canadian Implantable Defibrillator Study. Eur Heart 7 2000;21(24):2071-8.

8. Prevention of sudden death from ventricular arrhythmia. Canadian Cardiovascular Society 1999 consensus conference. Can 7 Cardiol 2000;16(Suppl C):1C-94C.

9. Gregoratos G, Abrams J, Epstein AE, Freedman RA, Hayes DL, Hlatky MA et al; American College of Cardiology/American Heart Association Task Force on Practice Guidelines/North American Society for Pacing and Electrophysiology Committee to Update the 1998 Pacemaker Guidelines. ACC/ AHA/NASPE 2002 guideline update for implantation of cardiac pacemakers and antiarrhythmia devices: summary article: a report of the American College of Cardiology/American Heart Association Task Force on Practice Guidelines (ACC/AHA/NASPE Committee to Update the 1998 Pacemaker Guidelines). Circulation 2002 106;16:2145-61.

10. Ruskin JN, Camm AJ, Zipes DP, Hallstrom AP, McGrory-Usset ME. Implantable cardioverter defibrillator utilization based on discharge diagnoses from Medicare and managed care patients. 7 Cardiovasc Electrophysiol 2002;13(1):38-43.

11. Kliegel A, Eisenburger P, Sterz F, Stix G, Holzer M, Losert H, et al. Cardiac arrest survivors who do no get implanted cardioverter defibrillators-automated external defibrillators could save their lives during a rearrest [abstract]. Acad Emerg Med 2001;8:432.

12. Stiell IG, Wells GA, Field BJ, Spaite DW, De Maio VJ, Ward R, et al. Improved out-of-hospital cardiac arrest survival through the inexpensive optimization of an existing defibrillation program: OPALS study phase II. Ontario Prehospital Advanced Life Support. FैAMA 1999;281(13):1175-81.

13. Stiell IG, Wells GA, Spaite DW, Lyver MB, Munkley DP, Field BJ, et al. The Ontario Prehospital Advanced Life Support (OPALS) Study: rationale and methodology for cardiac arrest patients. Ann Emerg Med 1998;32(2):180-90.

14. Cummins RO, Chamberlain DA, Abramson NS, Allen M, Baskett P, Becker $\mathrm{L}$, et al. Recommended guidelines for uniform reporting of data from out-ofhospital cardiac arrest: the Utstein style. Task Force of the AHA, the European Resuscitation Council, the Heart and Stroke Foundation of Canada, and the Australian Resuscitation Council. Ann Emerg Med 1991;20(8):861-74.

15. Brain Resuscitation Clinical Trial I Study Group. A randomized clinical study of cardiopulmonary-cerebral resuscitation: design, methods, and patient characteristics. Am 7 Emerg Med 1986;4:72-86.

16. Bunch TJ, White RD, Gersh BJ, Meverden RA, Hodge DO, Ballman KV, et al. Long-term outcomes of out-of-hospital cardiac arrest after successful early defibrillation. N Engl 7 Med 2003;348(26):2626-33.

17. Every NR, Larson EB, Litwin PE, Maynard C, Fihn SD, Eisenberg MS, et al. The association between on-site cardiac catheterization facilities and the use of coronary angiography after acute myocardial infarction. Myocardial Infarction Triage and Intervention Project Investigators. N Engl 7 Med 1993;329(8):546-51.

18. Frandsen F, Nielsen JR, Gram L, Larsen CF, Jorgensen HR, Hole P, et al. Evaluation of intensified prehospital treatment in out-of-hospital cardiac arrest: survival and cerebral prognosis. The Odense ambulance study. Cardiology 1991;79(4):256-64.

19. Nichol G, Stiell IG, Hebert P, Wells GA, Vandemheen K, Laupacis A. What is the quality of life of survivors of cardiac arrest? A prospective study. Acad Emerg Med 1999;6(2):95-102.

20. Bergner L, Bergner M, Hallstrom AP, Eisenberg MS, Cobb LA. Service factors and health status of survivors of out-of-hospital cardiac arrest. Am 7 Emerg Med 1983;1(3):259-63.

21. Stiell IG, Nichol G, Wells GA, De Maio VJ, Nesbitt L, Blackburn J, et al. Health-related quality of life is better for cardiac arrest survivors who received citizen CPR. Circulation 2003;108:1939-44.

22. Volpi A, Cavalli A, Franzosi MG, Maggioni A, Mauri F, Santoro E, et al. Oneyear prognosis of primary ventricular fibrillation complicating acute myocardial infarction. The GISSI (Gruppo Italiano per lo Studio della Streptochinasi nell'Infarto miocardico) investigators. Am 7 Cardiol 1989;63(17):1174-8.

23. Kliegel A, Eisenburger P, Sterz F, Holzer M, Losert H, Havel C, et al. Survivors of ventricular tachyarrhythmias due to a transient or reversible disorder have a high recurrence rate of lethal cardiac events. Resuscitation 2002;54(3):237-43.

24. Wyse DG, Friedman PL, Brodsky MA, Beckman KJ, Carlson MD, Curtis $\mathrm{AB}$, et al. AVID Investigators. Life-threatening ventricular arrhythmias due to transient or correctable causes: high risk for death in follow-up. $7 \mathrm{Am}$ Coll Cardiol 2001;38(6):1718-24.

Correspondence to: Dr. Graham Nichol, University of Washington, Harborview Prehospital Research and Training Center, 325 Ninth Ave., Box 359748, Seattle WA 98104, USA; fax 206 731-8277; nichol@u.washington.edu 